\title{
Blockchain Technology's Potential for Sustainable Tourism
}

\author{
Inessa Tyan ${ }^{1(\bowtie)}$, Mariemma I. Yagüe ${ }^{2}$, and Antonio Guevara-Plaza ${ }^{2}$ \\ 1 Faculty of Tourism, University of Malaga, \\ Campus of Teatinos, s/n, 29071 Málaga, Spain \\ inessa-jang@hotmail.com \\ 2 Institute of Tourism Intelligence and Innovation, University of Malaga, \\ Campus of Teatinos, s/n, 29071 Málaga, Spain \\ \{yague, guevara\}@uma.es
}

\begin{abstract}
Achieving sustainable tourism is a process that focuses on numerous goals and faces many challenges. The advent of disruptive technology like blockchain could help to tackle some challenges in sustainable tourism development and address its goals. This conceptual paper aims to discuss how blockchain technology could contribute to sustainable tourism. Precisely, the authors investigate the potential benefits of blockchain technology to disrupt tourism operations and boost local economy, manage food supply chain and mitigate food waste, achieve tourists' satisfaction, affect the tourists' sustainable behaviour, and address awareness rise issues. The authors conclude that blockchain technology has a potential to contribute to sustainable tourism development as well as the SDGs and propose the directions for future research.
\end{abstract}

Keywords: Blockchain technology $\cdot$ Sustainable tourism $\cdot$ SDGs

\section{Introduction}

The UN 2030 Agenda for Sustainable Development sets 17 sustainable development goals (SDGs) with the aim to end poverty, protect the planet, and ensure prosperity for all. Tourism, with its possible positive economic, social, and environmental effects, is influenced by the Agenda, though it is mentioned only three times - in the contexts of job creation, responsible production and consumption, and sustainable use of marine resources.

Sustainable tourism has been a major focus of tourism policy makers, destination marketing organisations, and tourism scholars for years. To highlight the significance of the sustainable tourism, United Nations Organisations proclaimed the year 2017 as the International Year of Sustainable Tourism for Development. Many scholars demonstrate their interest in the subject by publishing numerous papers that focus on different aspects of sustainable tourism. However, despite such interest, the empirical research shows that tourism is actually less sustainable than ever at the global scale [1, 2]. Therefore, the question how to achieve sustainable tourism is still open. Besides, the academia agrees that sustainable tourism implementation is under-researched area [3]. 
The scholars [4] suggest that the nature and achievement of sustainable tourism can be considered in a variety of ways. A great emphasis is put on the improved management and use of technological advancements that can efficiently respond to economic, sociocultural, and environmental problems [5, 6]. Technological advancements are broad-based and include a variety of production, information, and social technologies [7]. Though different technologies have implications for the sustainable tourism development, thanks to its unique characteristics, blockchain technology is capable to revolutionise sustainable tourism. Blockchain technology has gained a great interest from both practitioners and scholars quiet recently, yet various solutions to improve different sectors have been already provided. The attempts are being made to create more collaborative and integrated cities [8]; this will have a potential to provide more efficient and effective methods to live, work, and network through integrative platforms linking different stakeholders [9].

[10] assure that via blockchain implementation the tourism businesses will be able to manage sales, operations, finance, and administration related transaction, while capable to deal with external stakeholders, including the government. This will potentially contribute to sustainable tourism development, which cannot be achieved without the collaboration of all stakeholders.

This conceptual paper aims to contribute to existing literature on impacts of blockchain technology and focuses on the potential of blockchain technology to contribute to sustainable tourism development. In the further sections the authors provide an overview of sustainable tourism and blockchain technology, discuss how blockchain technology can be used to achieve sustainable tourism, elaborate on the ways the blockchain technology can be implemented in practice, and conclude and determine future research directions.

\section{Literature Review}

\subsection{Sustainable Tourism}

[11] defined sustainable tourism as tourism that takes full responsibility of its current and future economic, environmental, and social impacts, addressing the needs of the industry, the environment, tourists, and host communities. Generally speaking, sustainable tourism must satisfy the needs of the present tourists and tourism destinations in cope with providing opportunities for future development and maintaining heritage integrity, ecological integrity, biodiversity, and life-support system [12].

Sustainability and sustainable development gained high interest from the tourism scholars since the late 1980s [13]. Sustainable development approach is based on three pillars of sustainability: economic, social, and environmental. Economic sustainability refers to the efficiency of companies' activities in the long run; social responsibility is related to providing equal opportunities, respecting distinct cultures, reducing poverty and discrimination; and environmental sustainability refers to a proper management of scarce, especially not renewable, resources [11]. Similarly, many scholars regarded sustainable tourism as the interaction among economic, socio-cultural, and environmental aspects of tourism [14]. In order to be deemed as sustainable, a destination must be liveable, equitable, and viable [15]. 
However, in some research the intersection of three aspects of tourism is viewed as weak sustainability and great emphasis is put on strong sustainability [16]. Weak sustainability concept leads to endorsement of "sustainable" economic growth, whereas strong sustainability concept leads to conclusions that a steady-state economy is the most desirable outcome [17]. Furthermore, some academics have extended the threepillar concept of sustainability to four pillars including organisational development [18] or tourism value chain [19]. The advocates of the latter concept put emphasis on that sustainable tourism must find the ways to lower the harm that is simultaneously created along with the value for the tourists [20].

An extensive research on sustainable tourism has been matured with years; earlier papers focused on definitional and conceptual matters and provided frameworks to explain the sustainability construct; recent studies started to conduct more empirical research [21]. A more recent research focuses on sustainable tourism implementation [22], investigates gamification techniques and applications that can be used for achieving sustainable tourism [23], and proposes a multilevel approaches to understand sustainable tourism development [24]. [25] highlight the most popular researched topics in the domain, namely, tourism impact; sustainability assessment; development; visitors' attitudes; and planning. According to [21], since 2008 sustainable tourists' behaviour, event tourism, nature-based tourism, and climate change were predominant themes in sustainable tourism research. Though information technologies have been acknowledged to have a direct and significant impact on tourism industry, disruptive technologies did not receive much attention in sustainable tourism research.

\subsection{Blockchain Overview}

A blockchain is a distributed database that is comprised of a list of transaction bundles, named blocks, that are linked to each other. These blocks cannot be easily altered once they are accepted as parts of the total chain in a sophisticated non-centralised procedure. In order to change one block, every following block would also need to be changed that makes changing almost impossible [26]. There is no central authority who administers the blockchain, but the technology constitutes a peer-to-peer network where decentralised nodes keep copies of the whole blockchain. The so-called miners participate in the process of adding and verifying the new records. To add and verify the data, they solve a computationally difficult problem and then get rewarded for contributing their resources [27]. Every new block added to the chain contains a unique identifying code, the hash, based on its preceding blocks; this ensures more accuracy in data tracking and higher security [28]. Different blockchain-based platforms deploy socalled smart contracts that enable the trusted conclusion of online agreements between unknown parties. Digital currencies and smart contracts have the potential to disrupt many industries [29], including tourism. The major characteristics of blockchain technology and their possible links to sustainable tourism are provided in the Table 1. 
Table 1. Major characteristics of blockchain and the links to sustainable tourism

\begin{tabular}{l|l|l}
\hline Feature & Description & $\begin{array}{l}\text { Possible link to sustainable } \\
\text { tourism }\end{array}$ \\
\hline Disintermediation & $\begin{array}{l}\text { The peer-to-peer nature of the } \\
\text { blockchain means the absence of } \\
\text { a central authority }\end{array}$ & $\begin{array}{l}\text { Tourists and travel service } \\
\text { providers as well as local hosts } \\
\text { can directly contact each other }\end{array}$ \\
\hline Trust & $\begin{array}{l}\text { All participants can trust each } \\
\text { other and deal directly with each } \\
\text { other }\end{array}$ & $\begin{array}{l}\text { Tourists can express opinions and } \\
\text { evaluate their experiences with } \\
\text { different travel companies with } \\
\text { full transparency }\end{array}$ \\
\hline Costs & $\begin{array}{l}\text { Costs can be cut due to the } \\
\text { elimination of third parties }\end{array}$ & $\begin{array}{l}\text { Cost savings for both tourists and } \\
\text { travel service providers }\end{array}$ \\
\hline Traceability & $\begin{array}{l}\text { All transactions can be traced to } \\
\text { authenticate their origin and path }\end{array}$ & $\begin{array}{l}\text { Ensure that such products as } \\
\text { seafood, lumber and other } \\
\text { products sold as environmentally } \\
\text { friendly really are }\end{array}$ \\
\hline $\begin{array}{l}\text { Integration of } \\
\text { coins/tokens }\end{array}$ & $\begin{array}{l}\text { The coins/tokens are used for } \\
\text { more effective currency exchange, } \\
\text { loyalty program, and rewards for } \\
\text { review }\end{array}$ & $\begin{array}{l}\text { Both tourists and local } \\
\text { community can gain coins/tokens } \\
\text { for realising sustainable tourism } \\
\text { practices }\end{array}$ \\
\hline $\begin{array}{l}\text { Access to high- } \\
\text { quality data to } \\
\text { everyone }\end{array}$ & $\begin{array}{l}\text { All parties involved in a } \\
\text { transaction will have accurate, } \\
\text { timely, consistent and complete } \\
\text { data }\end{array}$ & $\begin{array}{l}\text { The availability of information } \\
\text { about the prices, travel service or } \\
\text { product to all parties ensures that } \\
\text { all tourists will be treated equally }\end{array}$ \\
\hline
\end{tabular}

Tourism industry is actively investing in blockchain-based start-ups. Among the tourism enterprises that already implement blockchain technology are TUI, adopting the technology in its booking, reservation, and payment systems [30]; CheapAir, Expedia, One Shot Hotels, and Webjet accepting bitcoins as a payment method [31]. Various blockchain solutions in tourism, for instance, Winding Tree, DeskBell Chain, TravelChain, invented their own coins or tokens.

Few academic papers on blockchain tourism research demonstrate the novelty of the topic. Existing studies mainly focus on general possible impacts of blockchain on travel, hospitality, food, and airline sectors [32, 33]. The blockchain adoption from smart tourism perspective is also discussed in some articles [34, 35]. Some authors [36] propose a blockchain basics criteria set for comparing the distributed applications (DApps). Recent research by [37] conceptualised the role of blockchain technology and cryptocurrencies in achieving tourism related SDGs.

Yet, the research focusing on the contribution of this disruptive technology to sustainable tourism development is very scarce. The practitioners seem to be more fast in addressing the SDGs via encouraging the sustainable tourism practices. Table 2 comprises several blockchain based companies that adopt sustainable tourism practices. 
Table 2. Blockchain based companies with sustainable tourism practices

\begin{tabular}{l|l}
\hline $\begin{array}{l}\text { Company } \\
\text { name }\end{array}$ & Sustainable tourism practices \\
\hline DeskBellChain & $\begin{array}{l}\text { The tourists can collect rewards for helping to clear up plastic litter on the } \\
\text { beach, for recycling, and for renting a bike instead of a hire-car }\end{array}$ \\
\hline Provenance & $\begin{array}{l}\text { Traces yellowfin and skipjack tuna from catch to consumers and digitally } \\
\text { reinforce the value of certification with Soil Association Organic }\end{array}$ \\
\hline IDGO & $\begin{array}{l}\text { Aims at strengthening the indigenous people autonomy and ethnic identity. } \\
\text { Tourists can obtain local merchandise discount. The revenue will be } \\
\text { returned to the community to help the environmental protection, education, } \\
\text { and cultural continuity }\end{array}$ \\
\hline Tranexus & $\begin{array}{l}\text { Will provide a travel assistant providing support for travel services with } \\
\text { eco-options and low-carbon choices }\end{array}$ \\
\hline NatureCoin & $\begin{array}{l}\text { The users get coins for recycling plastic. Later, they can change the coins } \\
\text { for local products }\end{array}$ \\
\hline
\end{tabular}

\section{Blockchain Technology and Sustainable Tourism}

\subsection{Potential of Blockchain Technology for Sustainable Tourism}

Because of its unique characteristics blockchain technology can have a tremendous impact on the business processes and the whole industries [38]. Sustainable tourism development is facing numerous challenges and barriers, for instance, large energy use and green gas emissions, inappropriate waste management and treatment, loss of biodiversity and habitat destruction, threats to heritage management and cultural integrity, lack of communication channels and information platforms [12]. In this section the authors focus on the possible potential of blockchain technology to tackle some of these challenges and discuss how this disruptive technology can be used to contribute to other domains of sustainable tourism. The domains of sustainable tourism that could be positively impacted by application of blockchain technology are summarised in Fig. 1 and explained in detail below. Though the effect of blockchain implementation on the achievement of SDGs is out of scope of this paper, the authors express their opinion regarding which particular SDGs can be affected by blockchain technology use. 


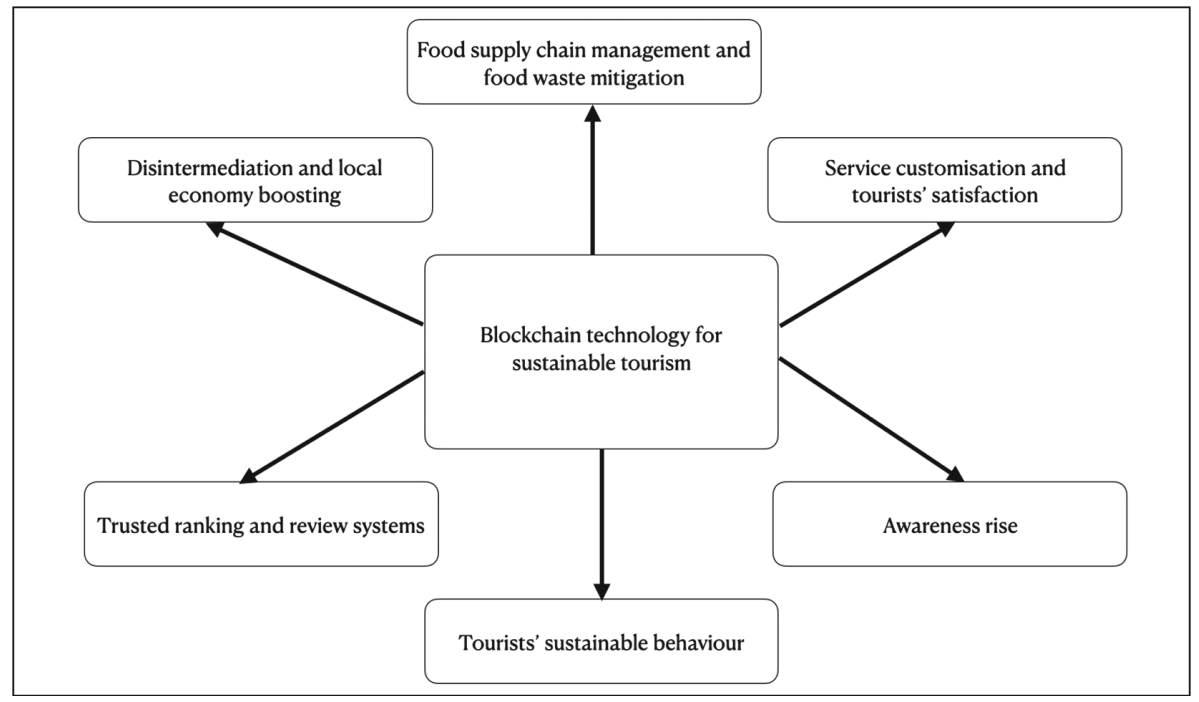

Fig. 1. Blockchain technology's potential for sustainable tourism.

\section{Disintermediation of Tourism Operations and Boosting of Local Economy and}

Culture. Providing economic benefits to local and other stakeholders as well as reaching tourists' satisfaction are among the important goals pursuing by sustainable tourism development [39]. Blockchain technology can help achieve these goals through enabling disintermediation of tourism operations. Blockchain technology can effectively remove the intermediaries because of its potential to build trust, ensure more secure information exchange, reduce costs, and enable transparency. Also, blockchain based cryptocurrencies enable simple, direct, and safe peer-to-peer transactions without the need for trusted third parties [40]. Moreover, blockchain technology can make transactions more equal and distribute similar powers to both providers and consumers of tourism services [41]. By virtue of these characteristics of blockchain technology, new players, both small companies and local tourism service providers, would appear in the tourism and hospitality market. As a result, the locals could sell tourism products to the tourists and in their turn, the tourists would access the authentic travel experiences. Through blockchain systems, the local businesses that conserve cultural heritage and traditional values as well as small businesses that sell local goods could offer their services and goods directly to the tourists and visitors. Blockchain ensures the transparency, quality, and origin of the data, so the tourists could verify the authenticity of purchased product and could be sure in its originality. Besides, they could be assured that the prices for goods and services are same for all. Also, rather than staying at a hotel, the tourists could have an opportunity to stay at some local's house and receive advices on authentic restaurants or/and sacred places to visit. Moreover, since blockchain technology allows to design and create digital currencies [39], local community could create their own money. The tourists could use local money to pay for goods and services at the destination, and thus boost local economy. 
Food Supply Chain Management and Food Waste Mitigation. From the perspective of contributing to environmental sustainability, blockchain technology can impact the food supply chain management and food logistics management [41]. Blockchain technology's properties, such as transparency, reliability, and invariability of data, can ensure a traceability system that will provide information about the origin, authenticity, processing, and retailing of food products. Such a traceability system will guarantee the food safety, confirm whether the food is really 'green', limit the chance of forgery or fraud, and increase tourist confidence and trust [34].

Another major sustainability challenge is waste mitigation [42]. As the hospitality sector grows, it produces more waste [43], and the major fraction of hospitality waste is represented by food waste [44]. Food waste mitigation could be achieved by effective stock management, excess food redistribution, recycling, and waste disposal [45]. Blockchain technology's decentralised, integrated architecture could improve stock management and facilitate excess food distribution.

Service Customisation and Tourists' Satisfaction. Tourists' satisfaction is one of the crucial goals aimed by sustainable tourism development. Tourism and hospitality companies put a great emphasis on customer management, tourist's experience, and service excellence to meet the tourists' needs and expectations with the aim to enhance the overall tourists' experience and achieve tourists' satisfaction [40]. Applying blockchain technology for guest services, such as tracking tourists, tracking luggage, facilitating travel insurance in case of flight delay or cancel, can significantly enhance tourists' satisfaction [32]. In addition, blockchain technology can provide services customisation without violating tourists' privacy. Using digital ID in blockchain technology, the tourists themselves choose which data and with whom they want to share their personal information [40]. Overall, blockchain technology can provide more accurate and trustworthy information enabling customised services resulted in better tourists' experiences and tourists' satisfaction.

Awareness Rise. According to [46] it can be stated that as all national tourism organisations, destination management organisations, local community, and tourists are essential levers in the transition to a sustainable future, it will be crucial to raise global awareness around sustainable tourism issues and increasing individuals' willingness to contribute to sustainable tourism development. In this case, blockchain may deliver transparent information regarding emissions, benchmarks, food supply chains, and tourists' choices. Genuine and audible informations on the blockchain could help to raise awareness and create incentives for sustainable behaviour of all interested parties.

Tourists' Sustainable Behaviour. Whereas some tourists tend to be pro-environmental and have a great interest in sustainable tourism practices, others do not care about the impacts their behaviour could have on local community and destination's environment. A blockchain-based rewarding system could be helpful in changing the tourists' behaviour. If the tourists could collect rewards for their sustainable behaviour, they would be more likely, for instance, to clear the beaches or collect plastic from the sea and bring it to established recycled centres. Or, the tourists would be more likely to prefer walking routes if they would receive cryptocurrency coins or tokens as a reward for their proenvironmental behaviour. Incentives are acknowledged to have a positive impact on 
individual's sustainable behaviour [23]. Blockchain technology could provide an excellent opportunity to create cryptocurrency-based rewarding system to encourage tourists' sustainable behaviour. The tourist would get tokens which they could spend on other goods and services in the host destination.

Trusted Ranking and Review Systems. When tourists with pro-environmental behaviours select an accommodation or restaurant, they often search reviews and ratings. However, the major problem can be inability to know which reviews are genuine and trustworthy and which are not [47]. The hotels, restaurant owners, or customers can manipulate the ranking and review systems [48]. Blockchain technology is capable to tackle this issue via its possibility to create a unique private key for each identity with several independent verification processes embedded into ranking and review systems [40]. This can ensure the reduced rates of manipulation or duplication of reviews. Blockchain technology could be applied to create a voting system that could be used to establish an immutable ranking of the best accommodations and restaurants with sustainable tourism practices.

Overall, based on the examples of potential effects of blockchain implementation on sustainable tourism, the authors argue that the application of blockchain technology can contribute to many SDGs, namely, SDG No.1 (no poverty), SDG No. 2 (zero hunger), SDG No. 5 (gender equality), SDG No. 8 (decent work and economic growth), SDG No. 9 (industry, innovation, and infrastructure), SDG No. 10 (reduced inequalities), SDG No. 11 (sustainable cities and communities), SDG No. 12 (responsible consumption and production), SDG No. 13 (climate action), SDG No. 14 (life below sea), SDG No. 15 (life on land), and SDG No. 17 (partnerships for the goals).

\subsection{Implementation of Blockchain Technology in Practice}

Within tourism industry, different stakeholders can benefit from blockchain implementation. For instance, some travel companies aim to implement blockchain technology in order to enhance tourist service quality and provide customised services [49], while others view the technology as a solution to reduce intermediary costs and travel agents' fees. Among the possible implementations of blockchain in tourism are: cryptocurrencies, smart contracts, and DApps.

Cryptocurrencies. Cryptocurrency is a digital currency where transactions are validated by all network members, rather than by central authority, at low costs [10]. Up to date, among a myriad of cryptocurrencies the most popular ones are Bitcoin, Ethereum, LiteCoin, Monero, Dash, BitcoinCash. Tourism destinations may accept and use cryptocurrencies; this will allow both tourists and residents to use cryptocurrency for purchasing different products, including flights and accommodation.

Smart Contracts. Smart contracts entail a coded programme of an agreement between two or more parties [10]. Applying smart contracts, tourism stakeholders (hotels, local shops, tourists) can automatically place orders, perform tasks, and issue payments without the need for approvals and instructions [36]. Within a tourism destination, smart contracts can automate the transactions related to purchases, salary payments, rewards issuance, hotel room key programming [50]. 
Tourism Related DApps. To improve the communication and interaction with the customers, tourism businesses can develop blockchain integrated DApps. Table 3 shows some of the existing tourism-related DApps. The tourists as well as service providers will benefit from using DApps in terms of significant cost savings, effective loyalty programmes, data sharing, and better identity management.

Table 3. Tourism related DApps

\begin{tabular}{|c|c|}
\hline DApp name & Description \\
\hline Winding Tree & $\begin{array}{l}\text { Using smart contracts and ERC } 827 \text { protocols, connects travellers directly } \\
\text { with service providers, thus providing best savings for the travel industry } \\
\text { and reducing the fees associated to the booking process }\end{array}$ \\
\hline Sandblock & $\begin{array}{l}\text { Aims to improve customer loyalty programs; is creating a much more } \\
\text { customisable token for all travel companies to make their loyalty scheme } \\
\text { more effective }\end{array}$ \\
\hline Accenture & $\begin{array}{l}\text { Introduces the Traveler Digital Identity System thanks to which airports can } \\
\text { accelerate the process of document verifications and, therefore, reduce the } \\
\text { lines in the airports }\end{array}$ \\
\hline Travelchain & $\begin{array}{l}\text { Intents to create an open-source system to manage the data of the tourists. } \\
\text { The systems will monitor and protect all travel data and users will get } \\
\text { tokens for sharing their data }\end{array}$ \\
\hline Trippki & Aims to develop better customer loyalty schemes \\
\hline $\begin{array}{l}\text { ShoCard and } \\
\text { SITA }\end{array}$ & Aims to better identity management in the tourism industry \\
\hline Lockchain & $\begin{array}{l}\text { Enables a direct marketplace for hotels, airlines; uses the decentralised } \\
\text { system for payment, property management, and booking processes }\end{array}$ \\
\hline
\end{tabular}

\section{Conclusion}

As popularity of blockchain technology and great interest in its implementation in various sectors are growing, the number of research papers dedicated to this technology grows as well. In spite of this, the tourism research on blockchain is still in its infancy. This conceptual paper intends to foster an academic discussion regarding blockchain and its possible impacts on tourism industry, specifically, on sustainable tourism development.

In the light of UN Agenda for sustainable development and its SDGs, this paper makes a contribution in terms of proposed achievement of sustainable tourism. This paper conceptualised the role of blockchain technology in its contribution to sustainable tourism. The authors have addressed the challenges and the goals of sustainable tourism by examining the potentials of blockchain technology. Blockchain technology can positively contribute to sustainable tourism development through boosting local economy, achieving tourists's satisfaction, and encouraging sustainable behaviour, and, therefore, can help address many SDGs. Nevertheless, blockchain technology itself may be quite unsustainable in terms of spending too much energy when creating the blocks. However, this issue has been addressing as there are different methods to create 
and validate the blocks that require less energy consumption [51]. As technical characteristics of blockchain that can impact the sustainability are out of scope of the present study, the possible negative impacts of blockchain technology on environment are not discussed in the present paper.

The paper also elaborated on blockchain implementation in practice. Cryptocurrencies, smart contracts, and DApps were conceptualised as the possible ways to implement blockchain technology.

One of the limitations of this paper is its scope; the authors explored few domains of sustainable tourism as to be impacted by blockchain technology. Additionally, the paper did not identify and elaborate about neither the barriers that impede blockchain technology adoption in the tourism sector, nor negative impacts of blockchain technology implementation on sustainability. Another limitation of the paper is in its type. Therefore, empirical research confirming the propositions made by this paper is of high importance.

Given the broadness of the topic and the limited number of relevant papers examining blockchain technology's benefits for sustainable tourism, the authors propose the following directions for further investigation. Future studies may examine the perceptions of different stakeholders towards blockchain technology's potential for sustainable tourism by conducting interviews. Also, considering the limited number of implemented blockchain solutions, the academia and specialists in the subject are invited to develop a real blockchain-based system on the basis of the propositions made in this paper and evaluate the results. Additionally, given many domains of sustainable tourism, the scholars are encouraged to explore the blockchain's impacts for different domains of sustainable tourism, for example, better communication, water consumption, benchmarking of tourism enterprises, biodiversity conservation, etc.

\section{References}

1. Rutty M, Gössling S, Scott D, Hall CM (2015) The global effects and impacts of tourism: an overview. In: Hall CM, Gössling S, Scott D (eds) The routledge handbook of tourism and sustainability. Routledge, Abingdon, pp 36-63

2. Scott D, Hall CM, Gössling S (2016) A review of the IPCC 5th assessment and implications for tourism sector climate resilience and decarbonization. J Sustain Tour 24(1):8-30

3. Dodds R, Butler RW (2010) Barriers to implementing sustainable tourism policy in mass tourism destinations. TOURISMOS Int Multi J Tour 5(1):35-53

4. Hall CM, Gössling S, Scott D (2015) The routledge handbook of tourism and sustainability. Routledge, Abingdon

5. Herrera-Cano C, Herrera-Cano A (2016) Maldivian disaster risk management and climate change action in tourism sector: lessons for the sustainable development agenda. Adv Sustain Environ Justice 19:113-131

6. Imon SS (2017) Cultural heritage management under tourism pressure. Worldw Hosp Tour Themes 9(3):335-348. https://doi.org/10.1108/WHATT-02-2017-0007 
7. Kouhizadeh M, Sarkis J (2018) Blockchain practices, potentials, and perspectives in greening supply chains. Sustainability 10(10):3652. https://doi.org/10.3390/su10103652

8. Snow C, Håkonsson D, Obel B (2016) A smart city is a collaborative community: lessons from smart Aarhus. Calif Manag Rev 59(1):92-108

9. Khan MS, Woo M, Nam K, Chathoth PK (2017) Smart city and smart tourism: a case of Dubai. Sustainability 9(12):2279

10. Boucher P, Nascimento S, Kritikos M (2017) How blockchain technology could change our lives. In: European parliamentary research service, scientific foresight unit. European Parliament, Brussels, pp 1-28

11. UNEP and UNWTO (2005) Making tourism more sustainable - a guide for policy makers. http://www.unep.fr/shared/publications/pdf/DTIx0592xPA-TourismPolicyEN.pdf

12. Pan SY, Gao M, Kim H, Shah KJ, Pei SL, Chiang PC (2018) Advances and challenges in sustainable tourism toward a green economy. Sci Total Environ 635:452-469

13. Hall CM (2010) Changing paradigms and global change: from sustainable to steady-state tourism. Tour Recreat Res 35:131-143

14. Kuhn L (2007) Sustainable tourism as emergent discourse. World Futures 63(3-4):286-297

15. Tanguay GA, Rajaonson J, Therrien MC (2013) Sustainable tourism indicators: selection criteria for policy implementation and scientific recognition. J Sustain Tour 21(6):862-879

16. Leonard D, Treiblmaier H (2019) Can cryptocurrencies help to pave the way to a more sustainable economy? Questioning the economic growth paradigm. In: Business transformation through blockchain. Palgrave Macmillan, Cham, pp 183-205

17. Daly HE (1991) Steady-state economics. Island Press, Washington, DC

18. Laririt MRI (2011) Sustainable tourism for biodiversity conservation - case study: El Nido Resorts, Palawan, Philippines. https://environment.elnidoresorts.com/2012/01/05/ sustainable-tourism-for-biodiversity-conservation/

19. Pomering A, Noble G, Lester WJ (2011) Conceptualising a contemporary marketing mix for sustainable tourism. J Sustain Tour 19(8):953-969. https://doi.org/10.1080/09669582.2011. 584625

20. Polonsky MJ, Carlson L, Fry M (2003) The harm chain: a public policy development and stakeholder perspective. Mark Theory 3(3):345-364

21. Ruhanen L, Weiler B, Moyle BD, McLennan CJ (2015) Trends and patterns in sustainable tourism research: a 25-year bibliometric analysis. J Sustain Tour 23(4):517-535. https://doi. org/10.1080/09669582.2014.978790

22. Maxim C (2016) Sustainable tourism implementation in urban areas: a case study of London. J Sustain Tour 24(7):971-989

23. Negruşa AL, Toader V, Sofică A, Tutunea MF, Rus RV (2015) Exploring gamification techniques and applications for sustainable tourism. Sustainability 7(8):11160-11189

24. Roxas FMY, Rivera JPR, Gutierrez ELM (2020) Framework for creating sustainable tourism using systems thinking. Curr Issues Tour 23(3):280-296

25. Buckley R (2012) Sustainable tourism: research and reality. Ann Tour Res 39(2):528-546

26. Nakamoto S (2008) Bitcoin: a peer-to-peer electronic cash system. Bitcoin.org. https:// bitcoin.org/bitcoin.pdf

27. Narayanan A, Bonneau J, Felten E, Miller A, Goldfeder S (2016) Bitcoin and cryptocurrency technologies: a comprehensive introduction. Princeton University Press, Princeton

28. Seffinga J, Lyons L, Bachman A (2017) The blockchain (r)evolution - the Swiss perspective. Deloitte, Switzerland

29. Giancaspro M (2017) Is a 'smart contract' really a smart idea? Insights from a legal perspective. Comput Law Secur Rev. http://www.sciencedirect.com/science/article/pii/ S026736491730167X 
30. Sixtin E (2017) TUI tourism group will adopt Ethereum blockchain technology. https:// btcmanager.com/tui-tourism-group-to-adopt-ethereums-blockchain/

31. Chokun J (2016) Who accepts bitcoins as payments? https://99bitcoins.com/who-acceptsbitcoins-payment-companies-stores-take-bitcoins/

32. Dogru T, Mody M, Leonardi C (2018) Blockchain technology \& its implications for the hospitality industry. Boston University

33. Udegbe S (2017) E: impact of blockchain technology in enhancing customer loyalty programs in airline business. Int J Innov Res Adv Stud 4(6):257-263

34. Baralla G, Ibba S, Marchesi M, Tonelli R, Missineo S (2018) A blockchain based system to ensure transparency and reliability in food supply chain. In: European conference on parallel processing. Springer, Cham, pp 379-391

35. Nam K, Dutt CS, Chathoth P, Khan MS (2019) Blockchain technology for smart city and smart tourism: latest trends and challenges. Asia Pacific J Tour Res 60:1-15

36. Ozdemir AI, Ar IM, Erol I (2019) Assessment of blockchain applications in travel and tourism industry. Qual Quant 54:1-15

37. Tham A, Sigala M (2020) Road block(chain): bit(coin)s for tourism sustainable development goals? J Hosp Tour Technol 11(2):203-222. https://doi.org/10.1108/JHTT-05-2019-0069

38. Treiblmaier H (2019) Toward more rigorous blockchain research: recommendations for writing blockchain case studies. Front Blockchain 2(3):1-15. https://doi.org/10.3389/fbloc. 2019.00003

39. Hall CM, Jenkins J, Kearsley G (eds) (1997) Tourism planning and policy in Australia and New Zealand: cases, issues and practise. Irwin Publishers, Sydney

40. Kizildag M, Dogru T, Zhang TC, Mody MA, Altin M, Ozturk AB, Ozdemir O (2019) Blockchain: a paradigm shift in business practices. Int J Contemp Hosp Manage 32(3):953975

41. Filimonau V, Naumova E (2020) The blockchain technology and the scope of its application in hospitality operations. Int J Hosp Manage 87:1-8

42. Thyberg KL, Tonjes DJ (2016) Drivers of food waste and their implications for sustainable policy development. Resour Conserv Recycl 106:110-123

43. Massow MV, McAdams B (2015) Table scraps: an evaluation of plate waste in restaurants. J Foodserv Bus Res 18:437-453

44. WRAP (2013) Overview of waste in the UK hospitality and food service sector. Oxon: WRAP. HFS001-006

45. Filimonau V, Delysia A (2019) Food waste management in hospitality operations: a critical review. Tour Manag 71:234-245

46. Dapp MM (2019) Toward a sustainable circular economy powered by community-based incentive systems. In: Business transformation through blockchain. Palgrave Macmillan, Cham, pp 153-181

47. Hammedi W, Kandampully J, Zhang TT, Bouquiaux L (2015) Online customer engagement: creating social environments through brand community constellations. J Serv Manage 26 (5):777-806

48. Önder I, Treiblmaier H (2018) Blockchain and tourism: three research propositions. Ann Tour Res 72(C):180-182 
49. Korže SZ (2019) How smart tourism embrace blockchains and smart contracts. Mednarodno inovativno poslovanje J Innov Bus Manage 11(2):32-40

50. Pilkington M (2017) Can blockchain technology help promote new tourism destinations? The example of medical tourism in Moldova. SSRN Electron J 1-8

51. OECD (2019) Blockchain technologies as a digital enabler for sustainable infrastructure

Open Access This chapter is licensed under the terms of the Creative Commons Attribution 4.0 International License (http://creativecommons.org/licenses/by/4.0/), which permits use, sharing, adaptation, distribution and reproduction in any medium or format, as long as you give appropriate credit to the original author(s) and the source, provide a link to the Creative Commons license and indicate if changes were made.

The images or other third party material in this chapter are included in the chapter's Creative Commons license, unless indicated otherwise in a credit line to the material. If material is not included in the chapter's Creative Commons license and your intended use is not permitted by statutory regulation or exceeds the permitted use, you will need to obtain permission directly from the copyright holder.

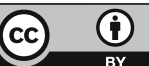

